\title{
THE GROUNDS FOR HIGHER EDUCATION TEACHERS TO ENGAGE IN MOOC DEVELOPMENT PROJECTS
}

\author{
UlfOlsson [ulf.olsson@su.se], Stockholm University, SE-106 91 Stockholm [https://su.se], Sweden
}

\begin{abstract}
The conditions for higher education teachers operating in a technology-enhanced education setting and an open educational context - such as Massive Open Online Courses (MOOCs) - are different when compared to traditional teaching methods (e.g. in a lecture hall). This study investigates the grounds for 20 teachers at Swedish Higher education institutions to be involved in MOOC development projects. Six categories are found and described; including curiosity, merits, teaching development, flexibility, as well as the possibility to disseminate their research and expand their professional networks. Interviewees believed that the work was a viable way to strengthen their research portfolio, while also making a limited effort for teaching, enhancing the dissemination possibilities and strengthening their research networks.
\end{abstract}

\section{Abstract in Swedish}

Det är stor skillnad för lärare inom högre utbildning att undervisa i öppna nätbaserade kurser jämfört med traditionella föreläsningar och klassrumsundervisning. Denna studie undersöker motiven för 20 lärare vid svenska universitet att engagera sig i projekt för att utveckla och undervisa i Massive Open Online Courses (MOOCs). Sex kategorier identifierades: Nyfikenhet; meriterande; utvecklande för deras undervisning; Flexibilitet; möjlighet att sprida egna forskningsresultat; och utöka deras professionella nätverk. Lärarna motiverade sitt arbete med att det var ett sätt att stärka sina forskningsmeriter genom en begränsad undervisningsinsats och att kunna sprida sina forskningsresultat och stärka sina respektive nätverk.

Keywords: Higher education, Open educational practises, Teachers, MOOCs, Open education, motives.

\section{Introduction}

Higher education teaching has evolved into new forms of teaching, characterised by the use of information technology (IT) and various degrees of openness. Generally speaking, all current teaching methods have some sort of IT element, and many MOOCs have been developed by higher education institutions (HEIs) in the last ten years (Bozkurt, Akgün-Özbek, \& ZawackiRichter, 2017). The conditions for the teachers operating in this technology-enhanced education, and open educational context, are different when compared to traditional teaching (i.e. in a lecture hall). Teachers are required to embrace IT and allow their teaching to be more open, which requires the ability to be scrutinized by colleagues and society outside of the campus. The teachers' engagement in this area cannot be taken for granted, therefore this current study emphasises the question of why teachers in higher education join MOOC-projects.

The combination of digital content and globalisation of higher education is influencing the teachers' work. This influence is argued to have "profound implications for all aspects of higher education" (Weller \& Anderson, 2013). Teaching has become interrelated both internationally due to globalisation, and internally due to technological infrastructure and increased professional involvement in the production of course material. The learning content has - to some degree - 
been separated from the teacher and, at the same time, has generated questions about ownership of the teaching material. The global trend to develop and provide open courses has increased. All of these changes have influenced the teaching profession and many teachers' daily work.

Although some institutions and individual teachers have developed new pedagogical approaches, the adoption of new IT for e-learning by the HEIs and academic staff has often been viewed as a disappointing and slow process, (Pundak \& Dvir, 2014; Salmon, 2014; Schneckenberg, 2009). A lack of clear evidence and benefits of IT in education are some explanations for the slow adoption rate. The different task to provide recorded and online accessible lecturing and to teach the "closed classroom" is also striking. MOOCs are an ideal case study for resilience as they are a product of the possibilities of digitisation and are both an opportunity and a threat to standard education practice (Weller \& Anderson, 2013). Accordingly, the grounds for higher education teachers to engage in MOOC development projects are investigated in this study. The following background section will describe the situation in greater depth.

\section{Background}

\section{Use of information technology in higher education}

Analysts argue that HEIs are lagging with regards to contemporary use of IT, even though university staff use several technical systems for their everyday work. Teaching and learning activities have not changed accordingly, while Learning Management Systems and other IT systems have been implemented for online courses as well as in classroom settings, and have been in use for several decades. The reasons for the slow adoption of IT in higher education teaching settings can be described in several ways. One view is that management is lagging when it comes to understanding the potential of IT. Another view is that teaching activities that include IT in a new way are often driven in projects as well as by engaged teachers. Schneckenberg (2009) drew some assumptions about eLearning relevant to the current study, and highlights two main barriers at the macro level that are hard to overcome. First is the autonomy of faculties with its resistance against institution-wide objectives. Secondly, academic research performance is superior when it comes to rating individual merits compared to teaching performance.

Other analysts argue that the use of IT in the teaching profession is lagging due to the teachers' resistance to it. This is described in several studies (Goodfellow \& Lea, 2007; Pundak \& Dvir, 2014; Salmon, 2014). This resistance may be caused by a lack of competence that leads the teachers to judge why, when and how to use IT in teaching (Schneckenberg, 2009).

Existing underlying innovation barriers need to be taken into account even if management finds IT highly relevant in teaching. Many voices are heard arguing for increased use of IT in teaching, but many HE teachers are hesitant in using it regardless of their access to relevant infrastructure and institutional policies. Implementation must address real learning needs, motivations of teachers, and be adapted to the contexts within different HEIs (Schneckenberg, 2009). Also, many teachers are IT-skilled and have developed their teaching practice to make comprehensive use of IT. One example of a teaching practice is the MOOC-trend to be described next.

\section{MOOCs}

MOOCs have existed for approximately a decade (Karunanayaka, Naidu, Rajendra, \& Ariadurai, 2018). Massive tells that the number of participants can be substantial and Open tells us that it is about courses that are open for anyone that wants to, and is able to, attend. Online implicates internet use for participation and communication. However, the degree of how these characteristics are fulfilled varies (Liyanagunawardena, Lundqvist, Mitchell, Warburton, \& Williams, 2019), and several of the characteristics listed are not new in HE, given that online and 
distance education has existed for a long time. Open education has also existed in different forms. However, regardless to what degree these characteristics are fulfilled and how novel the activity is, the teaching activity is different compared to the majority of the courses that $\mathrm{HE}$ teachers have been teaching up to now. "The teacher's role within a MOOC differs from most other educational contexts," (Ross, Sinclair, Knox, Bayne, \& Macleod, 2014; p.58).

The motives to develop and launch a MOOC differ among the HEIs, and it is often a combination of several objectives (Evans \& Gall, 2015). The universities face challenges that result from globalisation and technological innovations, and they wish to gain competitive strength (Schneckenberg, 2009). The ambition to follow other higher ranked universities is one important factor. The greater visibility of an HEI is also important - if tens of thousands of students register for one MOOC, it is fair to assume many more will be aware of the HEI. Those students would likely view it as a University interested in new forms of education, as well as being capable of financing, designing and launching a MOOC. A similar motive is to launch a MOOC in a field that will generate credits to a strategic research group (Olsson, 2017). This strategy is also important for the research group and the profile of the HEI. MOOCs give experiences and possibilities to learn about teaching and online learning (Pundak \& Dvir, 2014). Another motive is the responsibility of HEIs to increase the accessibility of higher education in developing countries in order to meet the increasing demand for education.

Regardless of the HEI's motives, the overall interest in open education such as MOOCs will influence the expectation on teachers to be part of the new practice. Zhen et al. argue that "Teaching a MOOC can be extremely difficult." (2016; p.207). Why should a teacher confront these challenges and join a MOOC-project? This is a particularly relevant question if their remuneration is unclear. The next sections of this paper contains studies that have attempted to answer this question.

\section{Openness}

Teaching practice is, in many aspects, the opposite of conducting research. Even if some teachers teach in large lecture halls with hundreds of students, the approaches to that type of teaching are still similar to teaching in a smaller classroom. "Classroom walls are increasingly permeable." (Siemens, 2008; p.3). The research practice - on the other hand - often includes collaboration in networks, making use of other researchers' results, citations, sharing and discussing drafts, conducting reviews and obtaining comments, rewriting and publishing in a journal that maximises the dissemination of the work carried out. The researchers' remuneration and credibility are strongly connected to their publications and are important when applying for a new position, applying for funds and discussing salary. The individual researcher needs to publish, be cited, and obtain high bibliometric-ratings to demonstrate academic talent and capacity. Funding bodies take bibliometric indicators into account when they decide whether or not to finance a research application. The phrase "publish or perish" is highly relevant in researchers" professional life. For the majority of academic staff, research is more important than teaching (Kreber, 2010; Schneckenberg, 2009). The individual teacher, on the other hand, likely neither wants nor needs to expand their teaching practice outside of the classroom.

An open attitude to teaching can be related to networking and collaboration, but the teachers' public approach in open education and MOOCs is complex. It is a way to break the "closed classroom" tradition as an academic and be more active in the public domain. The open educational practices can be depicted as the opposite of closed classroom practices and are described in the next section. 


\section{Open educational practices}

Open educational practices (OEP) is a core concept in the current study as "a broad descriptor of practices that include the creation, use, and reuse of open educational resources (OER), as well as open pedagogies and open sharing of teaching practices." (Cronin, 2017; p.16). MOOCs are a part of the open educational practice (Zheng et al., 2016) as well as open access (Weller \& Anderson, 2013). However, open teaching methods should not be confused with OEP since open teaching can take place without the use of OER, while OEPs are typically defined as a further step of the openness journey, which includes OER.

Many projects with the ambition to implement OERs have been launched since the concept was coined 25 years ago. Several studies have investigated teachers' inclination to use OER and its repositories. These studies are - to some extent - relevant to the current study as educational resources were developed during the design phase of the MOOC development projects. OER repositories are relatively unused and unknown compared with sites such as Khan Academy and TED (Nascimbeni \& Burgos, 2016). Similarly, few OERs were reused or redesigned by the teachers in the current study. Confusion over copyright rules and lack of IT support can be barriers to making use of OERs (Rolfe, 2012). Rolfe also found that teachers want recognition for time spent on development, and some of them also lack confidence (Rolfe, 2012).

The current study could have been a study of open educators, which, in some way, the interviewees are. The content is produced by the teachers, and the degree of planned interaction varies widely. However, this will not fit accurately according to Nascimbeni and Burgos' definition of the open educator as the one who conducts open teaching: "open teaching means to engage the learner in the social process of knowledge development instead of just letting them use the information and learning material presented by the teacher." (Nascimbeni \& Burgos, 2016; p.4).

\section{Other studies about incentives for the teacher}

Rules for remuneration in academia are often unclear, especially as academic staff are relatively autonomous in their daily work. The autonomy applies to both research and teaching with a high level of independence (Schneckenberg, 2009). The affordability to join a MOOC project can have imbedded motives of different perspectives, such as institutional strategies, the academics' science discipline and personal interest. Placing a development project, such as a MOOC project, as part of a long-term change of an institution needs careful implementation. Price (2015) states that in order to be sustainable, there needs to be ownership by teachers in the transformation in education, as they are required to implement it.

Hew and Cheung published (2014) a literature review of motives for MOOCs, and suggested three general incentives: The experience of teaching in a large global setting, including the challenge to develop material up to standard; the boost of personal recognition in the respective research field; and altruistic motives mainly explained as a possibility to increase student access to HE worldwide. A review and a study conducted by Zhen et al. are largely overlapping with the findings above as they found the motivation to teach MOOCs could be summarized as "global impact on students, professional growth, research opportunities, and enhanced name recognition" (Zheng et al., 2016, p.210) although the altruistic dimension wasn't reported.

The intention to reach new target audiences seems to be two-fold - both a wish to increase the outreach of one's teaching, along with a desire and an interest to participate in the development within the MOOC sector (Wannemacher \& Jungermann, 2015). A benefit of reaching out to a diverse global audience is the possibility to enhance a course's design and teaching activities with new perspectives and resources that haven't been possible in a local setting (Roth, 2013). This 
includes the possibilities to use new ideas to enhance a course's quality that can also benefit regular courses at a campus (Kolowich, 2013).

Kolowich (2013) also reported on egoistic motives such as an ambition to be the first among colleagues to offer a MOOC as a way to establish themselves as an expert in a particular field. To be the first to do something is commonly seen to add value to a professional's career.

The most common altruistic argument was the possibility to increase student access to higher education worldwide. Kolowich (2013) and Hew and Cheung's (2014) reporting on altruism can be related to the interest in developing and using OER for decreasing students' cost of literature (Belikov \& Bodily, 2016). The interrelationship among academic staff of both open content and processes is described by as "having a well-developed open digital identity; using social media for personal and professional use, including teaching; using both a VLE [Virtual Learning Environment] and open tools; using and reusing OER; valuing both privacy and openness." (Cronin, 2018; p.21). The common concepts behind the combination of open content and processes are openness (Arcos, Faems, Comas-Quinn, \& Pulker, 2017) and sharing (Acker, Buuren, \& Kreijns, 2013). This is also in line with a finding of teachers' preference of acknowledgement over financial or other awards (Arcos et al., 2017).

\section{Current study filling the gap}

A number of studies have investigated the reasons for the slow adoption of open approaches and OER (Cronin, 2017). However, very few research projects have focused on "one of the major missing links for openness in education to get mainstreamed, which is the need to empower teachers and lecturers to embrace open approaches in their daily work." (Nascinbeni \& Burgos, 2016; p.2).

In addition, few studies have taken the perspective of teachers and instructors compared to those of students and their behaviour (Kilis, Gülbahar, \& Rapp, 2016) especially with regards to studying MOOCs and open courses (Brown, 2016; Ross et al., 2014). "Surprisingly, little attention has been given to MOOC instructors, who play a significant role in making MOOCs happen" (Zheng et al., 2016; p.206). Therefore, the findings in the current study may contribute to the understanding of higher education teachers' grounds for joining MOOC projects and OEP.

\section{Method}

The empirical basis for assessing the grounds for HE teachers to engage in the projects was done through semi-structured interviews with 20 teachers at six Swedish HEIs. Respondents were from different disciplines and were at various stages of their careers. The method provided a more nuanced picture of the teachers' motivation than any quantitative data could be expected to generate. The methodology was judged to be appropriate for the current research goal.

All interviewees have been active in projects developing MOOCs at their respective HEIs. Their contribution to the MOOCs' design and production varied from one section of a course to the production of all of the material in a course. The degree of external support and the organisation around the design and production also varied. The teachers interviewed - eight women and twelve men - represent nine disciplines.

Thirteen face-to-face interviews were conducted at the teachers' respective universities and seven were conducted online. Fifteen of those interviews were conducted in Swedish and five in English. Any translated citation below is indicated. The interviews varied from 40 minutes to 100 minutes in length. 
The interviews were recorded and transcribed. MAXQDA 12 has been used for a thematic content analysis with an emphasis on the interpretation of the teachers' view of their grounds to engage in MOOC development projects (Kvale \& Brinkmann, 2014). The analysis identified, from a holistic overview, categories through an iterative process.

The transcripts were read once to get a first impression of the content. At the next step the transcripts were re-read and opinions, statements and activities were noted and coded. Important codes were brought together, which resulted in six categories being identified and characteristic quotes presented below in the results section. The categories are all relevant, important and interconnected, but an accurate ranking is not possible because of these interrelationships. A ranking is also not meaningful for a holistic understanding of the grounds for the interviewees to engage in MOOC development projects.

It is important for the question of validity to be aware of my role as an interviewer and interpreter of the transcripts. The circumstances of interviewing other teachers in one's own culture can be challenging (Hammersley, 2011). At the same time, expertise in the field of study is a prerequisite for conducting a valid study (Kvale \& Brinkmann, 2014), as is the ability to switch between the possibility to formulate informed questions and having an analytical distance.

I had no relation to the interviewees or the projects in question. No interviewee came from my affiliated university. I was not involved in any MOOC project of any kind that could be perceived as a competing activity. Still, the result should be interpreted with the knowledge that the analysis is based on the interviewees' retrospective statements when they had already decided to join the projects and start the work required.

\section{Findings}

The grounds for $\mathrm{HE}$ teachers to engage in MOOC development projects are through an iterative analysis divided into six categories. They are not ranked internally as the motives are intertwined and not feasible to measure reliably.

\section{Curiosity}

A common trait of the interviewed teachers was their description of themselves as curious for new pedagogy and technology, and to explore "what else" they could do in terms of teaching. The interviewees stated that they were curious about the new way to work and the challenge to put everything together. They wanted to be involved: "I am a Yes-man" [respondent 116, translated], as one teacher states. Two main arguments appear - firstly, to have the opportunity to change and teach in another way and, secondly, to have the possibility to promote their research. These expectations were combined with the challenge to condense their research in a very compressed and efficient manner that is useful for teaching in a MOOC.

The interviewees also expected to meet students from all over the world and have sessions with them. "It's a bit cool" [respondent 351, translated]. They appreciated the opportunity to meet another category of students compared to the ones they meet via on-campus teaching. Oncampus students mainly lack work experience but in the MOOCs, teachers expected to meet attendees from industry and business.

Even if some teachers argued that they had initial doubts, they believed it was better to "Try into their bare bones" [respondent 351, translated] rather than to sit and be sceptical. Initial doubts were overruled by the belief that this phenomenon was something to be expected in future teaching forms and society. To gain knowledge about MOOCs was valuable, even if everything was not viewed as perfect. 
To do something that few other teachers at their respective HEIs have done was also mentioned explicitly by one teacher as tempting. "First I see it's a good opportunity to be the first, and secondly there is a great need for the knowledge" [respondent 231]. The teacher's interest to develop the content is directly connected to their wish to develop as a professional teacher.

\section{Develop teaching}

To develop teaching was raised as an important ground to engage in MOOC projects. "See what we can do. How to record in another way. How to activate the students?" [respondent 344, translated] One teacher argued that since today's students are always connected, they [the teachers] should try to find a way to overbridge the practises. There was an implicit understanding that HEIs were not 'fast moving' in nature, but there was no outspoken criticism of any slow changes - merely an observation.

Most of the interviewed teachers explained that there were several challenges in producing an MOOC. One such challenge was how to design such a course in a way that makes it possible for the participants to learn. One teacher expressed that her lecturing at the campus had been stuck in a format, and she was motivated by the chance to learn new aspects of teaching. She explained that it was a possibility to conclude one's knowledge in a specific field and effectively teach the subject's essence. The experience from joining a MOOC project would allow for possibilities to use material and new teaching activities at a campus. Some of the time-consuming work in the projects can be justified by the possibility to also use the developed material on campus. "if you are keen to teach I think it's more rewarding to see how many people listen to you so I mean, so this is a good feeling from our side and that is an incentive" [respondent 197]

The relation between teaching and research was intertwined, but were very different processes. "At the same time you can take things from both of them and kind of improve your pedagogy" [respondent 151] Many of the interviewed teachers wanted to design MOOCs on a new topic or a topic that was in the development phase, and they were very keen on the possibilities to bring in the latest research findings. "I have to look at the most recent research result. Therefore, it helps me to keep up with most recent development in the literature." [respondent 231]. This makes research and the MOOC projects go hand in hand.

\section{Flexibility}

The format of the MOOCs was also expected to be different compared to teaching at the campus. The MOOC format does not require teachers to plan their ordinary teaching in class. The planning and production of material were different from the ordinary course development, and the MOOC format - with its attempts to combine research, education and communication activities - was promising. "It's the same people so for me personally it works fantastic good" [respondent 151] as one teacher explained.

The flexible format, without its bounds to a classroom, makes it possible to be anywhere in the world as long as the teacher keeps track of time. "Short and fast sessions. It fits my style." [respondent 116, translated]. However, the planned format and number of synchronous activities differs between the planned MOOCs.

\section{CV and merits}

The extra time that needs to be spent on developing a MOOC intrudes on the time for research, which is a problem as teaching is not viewed as being as meritorious as research. However, the development work is also something teachers can add to their CV's. One teacher, at the beginning of her academic career, mentioned the possibility to put the MOOC-experience on her $\mathrm{CV}$, while another teacher expressed the possibility to include the experience in his teaching 
portfolio when applying for an associate professor position. "Before, teaching was always my weak side in my CV, and now it is my strong side" [respondent 231], stated the teacher, explaining that experience with different teaching methods is valuable. The projects also make it possible to write and publish about pedagogical perspectives. To have a published research paper in pedagogy - in addition to research papers in their main field - was argued to be additionally valuable.

The described relationship between the teachers' benefits of obtaining more individual experience and the organisational benefits for the university was not clear. It's a possibility for an individual to contribute to the university's competitiveness by doing something that many course participants and other colleagues will recognise, instead of simply being one of many in their university teaching community. By gaining experience with MOOCs, the teacher becomes part of a very small and exclusive community that spreads the university's name around the world. It was, in fact, described as a possibility for a single teacher to contribute to the university's competitiveness.

Although the majority of interviewees expressed that the management was positive towards respective projects, this category also had another side. This was, as one teacher argued that the only system they - the teachers - have for merits is conducting research and to publish. He had never heard anyone from management promote his intentions and engagement. However, the project was internally initiated and funded. This issue is part of a bigger question about the relationship between research and teaching.

"At the very least, when you have to find your own funding, it will be a question of what should I prioritise. Should I spend time and money writing research applications and publish to increase the chances of getting these research funds or should I add time and resources to develop open courses which indeed are fun and may give me some credits in my career but gives me no money back." [respondent 324 translated]

\section{Disseminate research and promote the research group}

It is important in the academic world to promote specialised fields, and the MOOC projects make it possible to open up the educational material to a much wider audience. It is possible to have a greater reach with the research, results and the researchers' competence. The chance to spread research groups' accumulated knowledge in a new way was also mentioned as an advantage, as it is different when compared to ordinary research journals.

The aforementioned benefit is for the individual researcher and research group, but other perspectives were also expressed. Three of the teachers highlighted the importance to "educate the masses" as one teacher in health sciences argued: "health is very important for humanity and the possibility to bring out the knowledge, for free, globally was very pleasing. We have 19000 registered" [respondent 276, translated]. It was a way to reach out to so many more people than they will ever meet in the classroom.

\section{Expand the network}

The possibilities of dissemination and the hope for greater recognition is closely connected to the expressed wish of the respondents to expand their networks. One aspect that was appealing was the possibility to attract good students and the chance to recruit talents to the research group.

The majority of the interviewees expressed that it is a possibility to advertise oneself and be recognised. The personal brand is important for those who want an international career. One way to enhance these possibilities is to highlight and reference one's own publications. One teacher, 
who was also doing consulting work, expected his material to be good self-marketing. Other teachers also appreciated the possibility to meet a mix of academics, unemployed and employed people in the courses, which they hoped would expand their network both inside and outside academia. "You create synergies - we are testing new collaboration with industry which has effects like greater visibility" [respondent 163].

\section{Conclusions}

The overall result is aligned with Zheng et al. (2016) findings that the motives and engagement among MOOC instructors have multiple grounds. The interviewees in the current study have despite the lack of monetary rewards - become involved in the MOOC projects. That involvement may be an opportunity to sidestep what Schneckenberg (2009) describes as the marginalisation of teaching in academic culture, where status and monetary rewards are mainly based on research portfolios rather than e-learning innovations. Interviewees believed that the MOOC work was perhaps a functioning way to strengthen their research portfolio, while also making a limited project effort for teaching, enhancing the dissemination possibilities and strengthening their research networks.

The question about the grounds for teachers to involve themselves in MOOC projects cannot, however, be reduced to a question of teaching versus research and rewards. The current study's result should be interpreted as the background of the culture of HEIs and individual academics' views of academic autonomy and new public management. Academics may reject the idea to be recognised for a new activity they do not want to be involved in. "The current lack of a mandate through policy and recognition for OER contribution does not seem to be a key barrier to contribution." (Cox, 2016; p.210).

The teachers in the current study felt they did something voluntarily in projects that benefits themselves and their ambitions for their research group. Those actions were pragmatic and can be compared to other time-limited activities in project form that are motivated by special duties or activities that do not belong to a regular line of work and are outside of the regular framework.

Pedagogical concerns such as structure, accessibility and the students' knowledge acquisition were not brought up by the teachers in relation to their grounds for involvement in the MOOC projects. The time-consuming activity to produce a MOOC can be straightforward as it is possible to keep any epistemological understanding. The video seems to be a typical medium in the projects which is in line with findings by Stöhr et al. (2019). An advanced design of the student activities was not brought up as an important possibility.

Nascimbeni and Burgos' (2016) argument for a disconnection of the concept of open teaching and OER finds ground in the current study. Few revealed motives were related to OERs and even less had any familiarity to the concepts of the OER shown. One explanation for this can be the relatively little use of OER repositories in Sweden compared to some other countries. The cost of students' literature is not a big issue, and the global need for higher education may not be present in the daily work of an individual teacher. Digital course material and video are often used in teaching, but are not uploaded to fully searchable and accessible repositories despite good technical infrastructure. The limited use of OER may be due to as cultural aspects that producers, as creators of open content, are most concerned with acknowledgment. The importance of personal rewards may vary as Arcos et al. (2017) and Nascinbeni and Burgos (2016) reported low extrinsic motivation and low recognition from leaders.

Teachers' curiosity to develop teaching, flexibility, merits, research dissemination and to expand their networks are all grounds for engaging in MOOC projects. One appealing perspective on 
these conclusions is that all motives are relevant to the possibilities of keeping the epistemological understanding and to keep the idea of academic freedom.

The time issue aspect is crucial and, consequently, it was not obvious that teachers should join another MOOC project even if they mentioned several grounds for their current engagement. Zheng et al. (2016) argued that the cost-benefit equation of teaching MOOCs can adversely impact the quality. The curiosity factor fades away alongside the new experience. This hesitation, in combination with the costs to maintain the courses (Evans \& Gall, 2015), is a challenge for keeping the MOOCs active over time.

\section{Limitations and further studies}

This study does not discuss any pedagogical issues connected to the design of open education or the unbalanced residence of MOOC providers. The study has, on the other hand, focused and investigated what incentives the individual teacher had when they got involved in their respective MOOC projects. Although this study has been done within the context of Swedish higher education, the results may be relevant for similar contexts internationally. We should, however, be aware of the time aspect as the study was conducted in one phase (the technical and educational development time scale) and may not be transferrable to another time and phase.

Further studies can take several directions. One way is to make use of the Technology Acceptance Model (TAM) Çakıroğlu et al. (2017) or any model variation (Bachy \& Louvain, 2014) with a background of openness and the inclination to share among teachers. Further studies can also build on previous research on the identity of academics, e.g. McNaughton and Billet (2016) but also Kreber (2010).

\section{References}

1. Acker, F. van, Buuren, H. van, \& Kreijns, K. (2013). Resources : A Social Exchange Perspective Sharing OER as a Social Exchange Process. In R. McGreal, W. Kinuthia, \& S. Marshall (Eds.), Open Educational Resources: Innovation, Research and Practice (pp. 177-192). Commonwealth of Learning, Athabasca University. Retrieved from https://oerknowledgecloud.org/sites/oerknowledgecloud.org/files/pub_PS_OERIRP_web.pdf

2. Arcos, B. de los, Faems, B., Comas-Quinn, A., \& Pulker, H. (2017). Teachers' Use and Acceptance of Gamification and Social Networking Features of an Open Repository. European Journal of Open, Distance and E-Learning, 20(1). https://doi.org/10.1515/eurodl-20170008

3. Bachy, S., \& Louvain, U. de. (2014). TPDK, a new definition of the TPACK model for a University. European Journal of Open, Distance and e-Learning, 17(2), 15-39.

4. Belikov, O. M., \& Bodily, R. (2016). Incentives and barriers to OER adoption: A qualitative analysis of faculty perceptions. Open Praxis, 8(3), 235-246. https://doi.org/10.5944/openpraxis.8.3.308

5. Bozkurt, A., Akgün-Özbek, E., \& Zawacki-Richter, O. (2017). Trends and Patterns in Massive Open Online Courses: Review and Content Analysis of Research on MOOCs (20082015). The International Review of Research in Open and Distributed Learning, 18(5). https://doi.org/10.19173/irrodl.v18i5.3080

6. Brown, M. G. (2016). Blended instructional practice: A review of the empirical literature on instructors' adoption and use of online tools in face-to-face teaching. Internet and Higher Education, 31, 1-10. https://doi.org/10.1016/j.iheduc.2016.05.001 
7. Çakıroğlu, Ü., Gökoğlu, S., \& Öztürk, M. (2017). Pre-service Computer Teachers’ Tendencies towards the Use of Mobile Technologies: A Technology Acceptance Model Perspective. European Journal of Open, Distance and e-Learning, 20(1), 176-191. https://doi.org/10.1515/eurodl-2017-0011

8. Cox, G. (2016). Explaining the relations between culture, structure and agency in lecturers' contribution and non-contribution to Open Educational Resources in a Higher Education Institution. Thesis submitted for the Degree of Doctor of Philosophy to the School of Edu. University of Cape Town.

9. Cronin, C. (2017). Openness and Praxis: Exploring the Use of Open Educational Practices in Higher Education. The International Review of Research in Open and Distributed Learning, 18(5), 1534. https://doi.org/10.19173/irrodl.v18i5.3096

10. Cronin, C. I. (2018). Openness and Praxis: A Situated Study of Academic Staff Meaningmaking and Decision-making with Respect to Openness and Use of Open Educational Practices in Higher Education. Retrieved from https://aran.library.nuigalway.ie/handle/10379/7276

11. Evans, S., \& Gall, J. (2015). How MOOC instructors view the pedagogy and purposes of massive open online courses. Distance Education, 36(3), 295-311. https://doi.org/10.1080/01587919.2015.1081736

12. Hew, K. F., \& Cheung, W. S. (2014). Students' and instructors' use of massive open online courses (MOOCs): Motivations and challenges. Educational Research Review, 12, 45-58. https://doi.org/10.1016/j.edurev.2014.05.001

13. Goodfellow, R., \& Lea, M. R. (2007). Challenging e-learning in the university $\square$ : a literacies perspective McGraw Hill Society for Research into Higher Education \& Open University Press.

14. Hammersley, M. (2011). Methodology $\square$ : whoneeds it? Los Angeles: SAGE.

15. Karunanayaka, S. P., Naidu, S., Rajendra, J. C. N., \& Ariadurai, S. A. (2018). Designing Continuing Professional Development MOOCs to promote the adoption of OER and OEP. Open Praxis, 10(2), 179. https://doi.org/10.5944/openpraxis.10.2.826

16. Kilis, S., Gülbahar, Y., \& Rapp, C. (2016). Exploration of Teaching Preferences of Instructors' use of Social Media. European Journal of Open, Distance and E-Learning, 19(1), 1-18. https://doi.org/10.1515/eurodl-2016-0001

17. Kolowich, S. (2013, March 18). The Professors behind the MOOC. The Chronicle of Higher Education [Blog post]. Retrieved from http://www.chronicle.com/article/The-ProfessorsBehind-the-MOOC/137905

18. Kreber, C. (2010). Academics' teacher identities, authenticity and pedagogy. Studies in Higher Education, 35(2), 171-194. https://doi.org/10.1080/03075070902953048

19. Kvale, S., \& Brinkmann, S. (2014). Den kvalitativa forskningsintervjun. Lund: Studentlitteratur.

20. Liyanagunawardena, T. R., Lundqvist, K., Mitchell, R., Warburton, S., \& Williams, S. A. (2019). A MOOC Taxonomy Based on Classification Schemes of MOOCs. European Journal of Open Distance and E-Learning, 22(1), 85-103.

21. McNaughton, S. M., \& Billot, J. (2016). Negotiating academic teacher identity shifts during higher education contextual change. Teaching in Higher Education, 21(6), 644-658. https://doi.org/10.1080/13562517.2016.1163669

22. Nascimbeni, F., \& Burgos, D. (2016). In search for the open educator: Proposal of a definition and a framework to increase openness adoption among university educators. International Review of Research in Open and Distance Learning, 17(6), 1-17. https://doi.org/10.19173/IRRODL.V17I6.2736 
23. Olsson, U. (2017). Higher Education Lecturers Lived Experience of Going Public in MOOCs. Open Praxis, 9(3), 287-297. https://doi.org/10.5944/openpraxis.9.3.589

24. Price, D. (2015, April 16). What Will Education Look Like in a More Open Future? MindShift | KQED News [Blog post]. Retrieved February 21, 2019, from https://www.kqed.org/mindshift/40074/what-will-education-look-like-in-a-more-openfuture

25. Pundak, D., \& Dvir, Y. (2014). Engineering College Lecturers Reluctance to Adopt Online Courses. Retrieved September. European Journal of Open, Distance and E-Learning, 17(1), 210226. https://doi.org/10.2478/eurodl-2014-0014

26. Rolfe, V. (2012). Open educational resources: Staff attitudes and awareness. Research in Learning Technology, 20(1), 1-13. https://doi.org/10.3402/rlt.v20i0/14395

27. Ross, J., Sinclair, C., Knox, J., Bayne, S., \& Macleod, H. (2014). Teacher Experiences and Academic Identity: The Missing Components of MOOC Pedagogy. MERLOT Journal of Online Learning and Teaching, 10(1), 57-69.

28. Roth, M. (2013). My Modern Experience Teaching a MOOC. Chronicle of Higher Education, 59(34), B18-B21. Retrieved from https://www.chronicle.com/article/My-Modern-MOOCExperience/138781

29. Salmon, G. (2014). Learning Innovation: A Framework for Transformation. European Journal of Open Distance and E-Learning, 17(2), 219-235.

30. Schneckenberg, D. (2009). Understanding the real barriers to technology-enhanced innovation in higher education. Educational Research, 51(4), 411-424. https://doi.org/10.1080/00131880903354741

31. Siemens, G. (2008). Learning and Knowing in Networks: Changing roles for Educators and Designers.

32. Stöhr, C., Stathakarou, N., Mueller, F., Nifakos, S., \& McGrath, C. (2019). Videos as learning objects in MOOCs: A study of specialist and non-specialist participants' video activity in MOOCs. British Journal of Educational Technology, 50(1), 166-176. https://doi.org/10.1111/bjet.12623

33. Wannemacher, K., \& Jungermann, I. (2015). MOOCs from the Instructors' Perspective Klaus. Proceedings of the European MOOC Stakeholder Summit 2015, 81-85.

34. Weller, M., \& Anderson, T. (2013). Digital resilience in higher education. European Journal of Distance and E-learning, 2013(I). Retrieved from http://oro.open.ac.uk/36988/1/Weller_Anderson.pdf

35. Zheng, S., Wisniewski, P., Rosson, M. B., \& Carroll, J. M. (2016). Ask the Instructors: Motivations and Challenges of Teaching Massive Open Online Courses. Proceedings of the $19^{\text {th }}$ ACM Conference on Computer-Supported Cooperative Work \& Social Computing - CSCW' 16, 205220. https://doi.org/10.1145/2818048.2820082 